\title{
ANEXO 2: Listado de verbos incluidos en la búsqueda de corpus
}

La siguiente tabla contiene todos los verbos empleados para el análisis diacrónico de corpus presentado en el capítulo 5, ordenados atendiendo a la clase aspectual a la que pertenecen. Los subíndices que aparecen con algunos de ellos sirven para distinguir los diferentes significados que presentan (tanto en sincronía como en diacronía) como, por ejemplo, admirar ${ }_{1}$ 'tener singular estima' (estado), admirar $_{2}$ 'causar sorpresa' (actividad) y admirar ${ }_{3}$ 'contemplar' (actividad). Los significados de los verbos han sido contrastados utilizando el Diccionario de la lengua española (DLE), el Diccionario del castellano del siglo XV en la Corona de Aragón (DiCCA XV), el Vocabulario medieval castellano y el Diccionario español de documentos alfonsíes. Asimismo, la tabla recoge en la columna derecha el número de casos que se han tenido en cuenta para cada uno de los verbos.

\begin{tabular}{llr}
\hline Estado & & 449 \\
\hline abatir $_{2}$ & 'desanimar' & 1 \\
\hline admirar $_{1}$ & 'tener singular estima' & 36 \\
\hline amar $_{1}$ & 'tener amor’ & 119 \\
\hline conocer $_{1}$ & 'tener conocimiento de' & 107 \\
\hline identificar $_{2}$ & 'equiparar' & 12 \\
\hline preciar $^{\text {recordar }}{ }_{2}$ & 'tener aprecio' & 5 \\
\hline recordar $_{3}$ & 'tener en mente' & 23 \\
\hline rodear $_{1}$ & 'evocar' & 14 \\
\hline tener $_{1}$ & 'estar alrededor' & 38 \\
\hline
\end{tabular}

\begin{tabular}{llr}
\hline Actividad & & $\mathbf{1 2 1 8}$ \\
\hline acorrer & 'socorrer' & 4 \\
\hline acribillar & 'acosar física o psicológicamente' & 10 \\
\hline admirar 2 & $'$ 'causar sorpresa' & 11 \\
\hline admirar $_{3}$ & 'contemplar' & 9 \\
\hline agitar & 'inquietar, turbar' & 6 \\
\hline agraviar & 'hacer agravio' & 4 \\
\hline alimentar & 'dar alimento' & 2 \\
\hline amar 2 & 'hacer el amor' & 3 \\
\hline amparar & 'proteger' & 1 \\
\hline apalear & 'golpear' & 43 \\
\hline
\end{tabular}


(continuación)

\begin{tabular}{|c|c|c|}
\hline apedrear & 'lanzar piedras’ & 29 \\
\hline apretar & ‘oprimir’ & 38 \\
\hline arrastrar & ‘llevar tras de sí de un sitio a otro’ & 61 \\
\hline asediar & 'presionar insistentemente' & 18 \\
\hline atender & 'ofrecer cuidados’ & 13 \\
\hline atormentar & ‘causar dolor o aflicción’ & 6 \\
\hline ayudar & 'prestar cooperación' & 5 \\
\hline azotar & 'dar azotes' & 14 \\
\hline capitanear & 'dirigir’ & 1 \\
\hline castigar & 'infligir castigo' & 23 \\
\hline catar $_{1}$ & ‘buscar' & 4 \\
\hline cohechar & ‘forzar con violencia' & 2 \\
\hline combatir & 'atacar’ & 48 \\
\hline consolar & 'ofrecer consuelo' & 6 \\
\hline contemplar & ‘poner atención en’ & 11 \\
\hline contristar & ‘entristecer’ & 2 \\
\hline criar & ‘alimentar, cuidar, educar’ & 79 \\
\hline empujar & ‘hacer presión para desplazar’ & 47 \\
\hline enseñar & ‘educar’ & 5 \\
\hline evocar & 'recordar' & 17 \\
\hline forzar & ‘violar’ & 3 \\
\hline guardar & ‘cuidar’ & 2 \\
\hline guiar & 'dirigir’ & 105 \\
\hline honrar & 'enaltecer, dar honor' & 15 \\
\hline hostigar & ‘molestar’ & 1 \\
\hline humillar & 'herir la dignidad' & 3 \\
\hline incitar & ‘inducir a una acción’ & 1 \\
\hline investigar & ‘indagar acerca de algo o alguien’ & 4 \\
\hline llevar & ‘conducir de un lugar a otro’ & 2 \\
\hline maltratar & 'tratar con crueldad/dureza' & 122 \\
\hline martirizar & ‘atormentar o molestar’ & 4 \\
\hline menospreciar & ‘despreciar’ & 10 \\
\hline oír & 'percibir con el oído' & 119 \\
\hline oprimir & ‘someter’ & 30 \\
\hline pendrar & 'retener' & 3 \\
\hline percibir & 'captar por uno de los sentidos' & 2 \\
\hline proveer & ‘suministrar’ & 1 \\
\hline
\end{tabular}


(continuación)

\begin{tabular}{llr}
\hline punir & 'castigar' & 14 \\
\hline remolcar & 'desplazar tirando' & 1 \\
\hline sacudir & 'golpear' & 12 \\
\hline señorear & 'dirigir o mandar' & 1 \\
\hline servir & 'asistir' & 2 \\
\hline sitiar & 'cercar para apresar' & 4 \\
\hline transportar & 'llevar de un lugar a otro' & 37 \\
\hline ver & 'percibir por los ojos' & 120 \\
\hline vigilar & 'observar cuidadosamente' & 52 \\
\hline zarandear & 'mover con violencia' & 26
\end{tabular}

\begin{tabular}{|c|c|c|}
\hline Realización & & 383 \\
\hline conocer $_{2}$ & 'tener relaciones sexuales' & 6 \\
\hline conocer $_{4}$ & 'tener contacto por primera vez' & 40 \\
\hline despedazar & ‘hacer pedazos’ & 36 \\
\hline destrozar & ‘aniquilar’ & 30 \\
\hline identificar $_{3}$ & 'pedir datos personales' & 5 \\
\hline identificar $_{4}$ & 'dar datos personales' & 5 \\
\hline neutralizar & 'contrarrestar o anular el efecto' & 12 \\
\hline olvidar & ‘dejar de tener en la mente’ & 78 \\
\hline quemar & 'destruir con fuego’ & 79 \\
\hline recordar $_{1}$ & 'pasar a tener en mente' & 15 \\
\hline recordar $_{4}$ & ‘hacer recordar’ & 1 \\
\hline rodear $_{2}$ & 'cercar o dar la vuelta' & 15 \\
\hline traer & 'trasladar al lugar en donde se habla' & 60 \\
\hline transportar 2 & ‘enajenar de la razón’ & 1 \\
\hline Logro & & 1150 \\
\hline abatir $_{1}$ & ‘derribar’ & 46 \\
\hline arrollar & 'llevarse por delante’ & 44 \\
\hline catar $_{2}$ & 'encontrar’ & 1 \\
\hline clamar & ‘llamar’ & 16 \\
\hline conocer $_{3}$ & 'reconocer' & 40 \\
\hline derribar & ‘tirar al suelo’ & 89 \\
\hline descartar & ‘excluir o eliminar’ & 8 \\
\hline descubrir $_{1}$ & ‘encontrar’ & 38 \\
\hline descubrir $_{2}$ & 'poner al descubierto' & 9 \\
\hline
\end{tabular}


(continuación)

\begin{tabular}{|c|c|c|}
\hline detectar & ‘descubrir’ & 9 \\
\hline eliminar & ‘matar’ & 31 \\
\hline encerrar & $\begin{array}{l}\text { 'meter en lugar del que no se puede } \\
\text { salir' }\end{array}$ & 1 \\
\hline encontrar $_{1}$ & 'hallar' & 145 \\
\hline encontrar $_{2}$ & 'golpear con fuerza' & 30 \\
\hline enviar & $\begin{array}{l}\text { 'hacer que algo se dirija a alguna } \\
\text { parte' }\end{array}$ & 17 \\
\hline hallar & 'encontrar’ & 147 \\
\hline herir & ‘dañar’ & 2 \\
\hline identificar $_{1}$ & 'reconocer' & 54 \\
\hline llamar & ‘invocar’ & 32 \\
\hline localizar & ‘averiguar la localización’ & 62 \\
\hline matar & 'quitar la vida' & 111 \\
\hline mencionar & ‘hacer mención’ & 36 \\
\hline nombrar & ‘hacer mención’ & 52 \\
\hline reconocer & ‘identificar’ & 1 \\
\hline tener $_{2}$ & ‘alumbrar’ & 5 \\
\hline vencer & 'derrotar' & 122 \\
\hline Total & & 3200 \\
\hline
\end{tabular}

